\title{
Performativity and Metaphor in New Materialist Media Theory
}

NIALL FLYNN, University of Lincoln

\begin{abstract}
Some media theorists have begun to rethink the material basis of media in light of 'new materialist' thought. This involves expanding the concept of media to include the temporal and indeterminate processes involved. The process of mediation, rather than stable media objects, emerges as the point of departure. The basic claim of this essay is that media theory's recent embrace of material forces and practices should not take place as refusal of representation. The critical context of new materialism, which concerns the instability between objects and their representation, has led some media theorists to reconsider the relation between media theory and its objects of study in the world. This takes place in some cases in the name of a performativity of method - an appeal to the creative, practical, and material forces of media-theoretical research that reconceives the theory-world relation in these terms. Metaphor, the rhetorical transfer of meaning from one term to another, and usually understood as supplemental, can also be conceived as a material process of mediation, if we think in terms of a new materialist perspective. Thinking about metaphor in this way allows us to carry new materialism's important insights on materiality, meaning, mediation and method further.
\end{abstract}

\section{KEYWORDS}

Metaphor; Methodology; New Materialism; Performativity 
Media have a complex relation to the world. Humanities research requires media in some form to express its ideas and findings; traditionally this has taken a written, textual, and published form. The various methodological approaches in the humanities have more or less explicit views on the media-world relation. Media theory is the discipline that conceptualises this relation most directly, and has approached it in numerous ways. For a long time, media were understood to express or represent the world in a process similar to language: to form an image of it and reproduce it, although always at some remove. This understanding requires a rhetorical transfer from objects in the world to theoretical representation; in other words, a method. Separation between the world and its theoretical image, however, has been questioned on numerous grounds. One context for this questioning is the breakdown of this linguistic model and its displacement by non-, post-, and even anti-representational approaches. 'New materialism' in cultural theory is one recent exploration of this context.

The basic claim of this essay is that media theory's recent embrace of material forces and practices - explored in broader cultural theory and humanities under the 'new materialist' rubric - should not take place as an outright refusal of representationalism-which is the philosophy of metaphorical representation based on an ontological separation between individual entities and descriptions of them. The type of new materialism considered in this essay, building on Karen Barad's approach in Meeting the Universe Halfway (2007), ${ }^{1}$ reconceives the world through ontological and epistemological insights on entanglement and relationality. Matter and meaning are entangled, an argument Barad takes from quantum physics. $^{2}$ In cultural theory and the humanities, this means that representational entities no longer have the interpretive power they once had. The critical context of new materialism, which concerns the instability between objects and their representation, and which will be introduced further below, has led some media theorists to reconsider the relation between media theory and its objects of study in the world. This takes place in some cases in the name of a performativity of method - an appeal to the creative, practical, and material forces of media-theoretical research that reconceives the theory-world relation in these terms. Metaphor, the rhetorical transfer of meaning from one term to another, and usually understood as supplemental, can also be conceived as a material process of mediation, if we think in terms of a new materialist perspective. Thinking about metaphor in this way allows us to carry new materialism's important insights on materiality, meaning, mediation, and method further.

Section one of this essay lays out the terms of new materialist thought and shows how the refusal of representation is replaced by an appeal to performative approaches. Section two argues that while this a valid and valuable critical move, it retains problematic elements. By refusing representation, it reproduces the exclusionary structures it seeks to develop, replacing one metadiscourse with another. Section three explores how the appeal to performativity could embrace metaphor, understood here in a new materialist perspective as a constitutive and material process of mediation, in order to contribute to the ongoing reconceptualisation of materiality. Section four illustrates the essay's ideas by examining the trend in media studies that claims cinema itself as a type of theory. This 'film-as-theory' discourse, despite appealing to a performativity, separates theory and the film text in a way that presupposes an instrumental understanding of metaphor. I conclude the essay by considering what media theory offers new materialist thought.

\footnotetext{
${ }^{1}$ Dolphijn and van der Tuin's (2012) collection of interviews and essays is a good introductory text to the area.

2 And which is gaining more traction since the publication of her book; Mark van Raamsdonk (2010) explores the dynamics, properties, and structures of entanglement as a fundamental physical principle.
} 


\section{Performativity in New Materialist Media Theory}

New materialist insights have challenged some of the methodological bases of media theory. The relation between theory and the world, which is assumed or explicitly stated, depending on the author's methodological views, is one such basis. New materialism explores topics like representation, language, agency, and the limits of human reason through an emphasis on matter: materiality and things, rather than cognitive subjects, hold significance. New materialism challenges the idea that language and metaphor can accurately represent things in the world. The transcendent boundary between metaphorical language and objects in the world is effaced in this frame. Questions of being and knowing are thus addressed at the same time: matter and meaning are entangled and inseparable (Barad 2007). ${ }^{3}$ What this coconstitution and co-emergence of matter and meaning, things and ideas, means for academic knowledge production is a new conceptualisation of the relation between theories and methods, on the one hand, and their objects of study in the world, on the other. This is known as performativity; here is Barad's understanding of the term:

A performative understanding of discursive practices challenges the representationalist belief in the power of words to represent preexisting things. Unlike representationalism, which positions us above or outside the world we allegedly merely reflect on, a performative account insists on understanding thinking, observing, and theorizing as practices of engagement with, and as part of, the world in which we have our being. $(2007,133)$

Performativity involves a practical, rather than linguistic, experience of things. It challenges representation by closing the barrier between the world and our theoretical representations.

In the context of these ideas, media theory's basic concepts of medium and mediation have shown to be lacking, and a range of authors working in different areas are rethinking media on an expanded basis in line with the new materialist critique of representation (Bogost 2012; Kember \& Zylinska 2012; Parikka 2015; Herzogenrath ed. 2015). They understand media in a non-representational light, no longer as a model or image of the world, but as bound up with in complex ways with multiple phenomena. These phenomena, too, are given a twist-they are neither wholly natural nor social; materiality is their lowest common denominator. All of this involves a shift from thinking about media as stable and discrete objects to temporal and temporary processes of mediation, that is, an expanded perspective on media. This expanded concept of media focuses on the material process of mediation. This term occurs throughout this essay and it refers to a new conception of what mediation entails, beyond its purely representational aspects, and beyond Barad's vision of mediation as well. Theorists like these consider media no longer as simple nodes of communication between senders. In this model, $\mathrm{x}$ passes on information of some kind to $\mathrm{y}$, and the method of communication is the medium. This is a representational model, where the middle term, the medium, has little significance. In a new materialist understanding of this process, which focuses on its underlying material aspects, the medium is a constitutive element. ${ }^{4}$ How it affects both ends of the process, and what it does in between them, are more important than the end points; it interacts with other mediations and other things in the world. Kember and Zylinska explain that mediation is not equivalent to technology: it involves the entanglement of humans and machines, technologies

\footnotetext{
${ }^{3}$ In media theory, Jussi Parikka (2015) signals this entanglement with his 'medianatures' concept, which is taken from Donna Haraway's 'naturecultures'. Media and nature are intimately connected: media are constituted by bits of the earth, and the earth is itself mediated by technological processes.

${ }^{4}$ This builds upon the heritage of Marshall McLuhan's pronouncements of the medium's importance.
} 
and users. It is a process of which we are a part and cannot extricate ourselves, an 'ongoing process of becoming-with that is neither revealed nor concealed but rather apprehended intuitively-inevitably from inside the process' (Kember and Zylinska 2012, 40). Our understanding of media occurs with and through media. This exploration of the material basis of media has led to an expansion of the media concept far beyond traditional understandings of the transmission of information. This is what the material process of mediation refers to.

New materialisms do not concern developing better understanding or comprehension- those remain representationalist notions. They concern action, experience, and their relations with academic theorisation. The media theory approach to this has turned on material and creative practices. In this context, the material processes and practices of mediation have become significant points of enquiry. Consider these indicative lines from Jussi Parikka:

In addition to the realisation that theory should be seen as situated practice, we can also consider practice as theory. Practices are in themselves theoretical excavations into the world of 'things', objects of (cultural) research conducted in a manner that makes the two inseparable. Practices probe, investigate, track, interrupt, intervene and question. Practices point towards the primacy of the experiment as a formation inseparable from theory. Practices are theories in the very dynamic mode that makes 'theories work.' $(2011,34)$.

For Parikka, theory and practice are not separate or irreconcilable things; indeed, theory should be conceived as a form of practice. This is a result of taking materiality seriously. Materiality is not just things we can touch or move. Practices, though symbolic, also contain material elements: there are materialities of creativity, lived experience, and the unknown. These things have material relations in turn to other things in the world. Such an understanding works by undoing previously rigid interpretations of materiality. Theories of media fold in with this process whereby a description of a media phenomenon cannot be separated from its context, that is, taken outside medial or mediated conditions. Further to this line of enquiry, there is an emphasis on creativity in some recent media theory. Creativity is one way of emphasising materiality. One recent publication reimagines media studies as a kind of making:

It's a kind of media studies which has making at its front and centre. It's about being able to do things with media - not just talk about what other people do with them, or what they do to us. It's about being hands-on, which means it's still about ideas and critical engagement, but expressed through making things rather than just writing arguments. (We can still write too, of course, but the writing might be more powerful when informed by the experiences of making and exchanging). (Gauntlett 2014, 3)

Creativity is exalted here. Gauntlett's book declares a creative turn in media studies. This emphasis on creativity has led to new forms of media studies beyond written theory, such as the academic video essay. ${ }^{5}$ There are similar changes in the practical aspects of academic work, such as publication and distribution. ${ }^{6}$ This kind of approach to the creative, practical, and material aspects of media theory is a valid and vital challenge to representational strictures and representationalism, which strictly separates theoretical representations from

\footnotetext{
${ }^{5}$ The online journals [in] Transition (http://mediacommons.futureofthebook.org/intransition/) and Audiovisual Thinking: (http://www.audiovisualthinking.org/), for example, are dedicated to the video essay form.

${ }^{6}$ For example, Open Humanities Press (http://openhumanitiespress.org/) and the recently launched Open Library of Humanities (https://www.openlibhums.org/) operate through online, open access models.
} 
their real-world objects.

In written media theory, performativity has become a buzzword, and it too promises to enact novel theory-world relations. The performativity of media theoretical methods is what I focus on in this essay. Performativity is posed in these debates against the ontological and epistemological assumptions of classical representation, which have roots in the seventeenth century and the laws of Newtonian physics (Barad 2007, 21). In this model, there are discrete objects in the world that can be represented, and these objects have a separate existence from their subsequent representations. Barad appeals to quantum physics pioneer Niels Bohr's uncertainty principle to trouble this idea. Without going into too much detail, it will suffice to say that the uncertainty principle is drawn from an experiment on electrons demonstrating how measuring apparatuses interfere with their objects of study. The experiment shows that measurement and representation are not transparent actions. In humanities research, this means that our methods are not objective, and do not leave the world untouched, that they perform certain transformations on the world. ${ }^{7}$ In light of this, Barad argues that a 'cut' is enacted between the (subjective) observing agent and the object $(2007,330)$. It is materially enacted, rather than being inherent to either. This cut is part of the methodological apparatus and delineates between them. Kember and Zylinska (2012) adopt this performative notion of the cut in media theory in order to address how media fail to represent the world's dynamics. To illustrate this, they analyse photography as a performative and material practice, against its usual reading as a representational, indexical apparatus. Photographic mediation enables us to experience the duration of time through by enacting the cut. Each photograph cuts through the 'flow of mediation' (Kember and Zylinska 2012, 71); it transforms matter, and thus photography cannot be understood adequately as a series of discrete and separate media objects. Kember and Zylinska are led to ask the ethical question, 'what does it mean to cut well?' (ibid.). The cut is one example of how media theorists challenge hard and fast distinctions between theory and the world. However, the performative method of cutting only goes so far, which Kember and Zylinska acknowledge $(2012,52)$. Despite its challenges to representationalism, performative and material practices are not without their problems and limitations.

\section{Refusing Representation, Reproducing Representation}

I would like to argue that the appeal to performativity in the above media theorists takes place, to varying degrees, as a refusal of representation. This refusal reproduces the exclusionary structure of representation, which is based on identifying an object's distinct and individual characterises and contrasting it to other objects. Barad lays out her reasons for this refusal:

as long as representation is the name of the game, the notion of mediation-whether through the lens of consciousness, language, culture, technology, or labor-holds nature at bay, beyond our grasp, generating and regenerating the philosophical problem of the possibility of human knowledge out of this metaphysical quarantining of the object world. $(2007,375)$

For Barad, representation distances us from elements in the natural world, and human knowledge is only made possible through this distancing. In her account, mediation is a

\footnotetext{
${ }^{7}$ John Law (2004) discusses this in the context of social sciences methods.
} 
function of representationalism, but considering mediation as a material process challenges this notion. This will be analysed further below. The film-as-theory debate, which will also be considered further below, similarly illustrates the stakes of refusing representation in a media theory context:

As unlikely as it might seem at first, the inherent continuity between cinema and life becomes apparent when one abandons the very representational compartmentalizations that I believe are also at the heart of our failure to do away with war, hunger, or environmental collapse. (del Río 2008, 215)

This view asserts a performative conception of cinema, which advocates closing the gap between cinema and the natural world, and which opposes an understanding of cinema as a representational apparatus. For del Río, it is important to realise the depredations of systems of representation - her claims are broad in this regard. For these theorists, representation has to be superseded. But their vision of this move, cleanly replacing one framework of understanding with another, is problematic. We do not have to treat the legacy of humanities approaches as misguided, or go on to directly replace one methodological orthodoxy with another. Reacting against representation in this way is not the gesture that is needed. We should continue to analyse the performativity-representation relation rather than simply abandoning it. ${ }^{8}$ In a recent publication on this theme, Federica Timeto emphasises the entanglements of onto-epistemological frameworks like representation and performativity (2015). In so doing, Timeto further nuances their relationship, showing how they lack independent existences. Representation also consists of performative elements, and focusing on materiality, as scholars in this area have done, does not guarantee overcoming representation. Representation is also enacted through material practices:

Potentially, matter exists in two states at the same time. Matter, thus, is substantially performative and informational, never inert and stable. Conversely, information and representation acquire a 'mattering' performativity as they cannot be separated from what they describe. (Timeto 2015,3)

This puts another spin on representation, showing that we cannot simply oppose it with new terms like performativity or materiality. Opposition between these categories suggests that we stand to create something new by abandoning representationalism. It is as if representation's negative critique of objects had deleterious effects, as in del Río's analysis, and an affirmation of their productive forces, on the other hand, was the more shrewd and ethical response. ${ }^{9}$ The oppositional structure of 'non-representational theory' (Thrift 2008), to give another example, reproduces the same kind of rhetorical structure it reacts against by defining itself against representational theories. Developing performative and material practices does not have to be part of an anti-representational move or a refusal of representation; this is itself a move immanent to representationalism. An alternative is to conceptualise the metaphorical aspects of methods in a new materialist light, understanding metaphor as always already material, and bound up with matter and meaning, and to acknowledge the complexity of representation in the first place, including its performative, material aspects.

Despite new materialist media theory's significant reassessment of disciplinary and

\footnotetext{
${ }^{8}$ Of course, concentrating on the world of matter does not mean that representation should not be abandoned altogether. Timeto $(2015,64-68)$ shows how theorists of materiality like Donna Haraway, N. Katherine Hayles, and Karen Barad acknowledge this.

${ }^{9}$ Benjamin Noys (2010) analyses this trend in critical theory and philosophy under the name of 'affirmationism'.
} 
methodological norms, it has retained a peculiar relation to metaphor. There has been no adequate assertion of metaphorical expression on the same terms. This is an important omission because, even as these authors rail against language and representation by developing a theory of performativity, their work relies on the same textual basis, which is replete with familiar rhetorical figures. For example, Barad explains that the visual metaphor of reflection is privileged in humanities. Reflection offers a representational mirror, and the tradition of reflexive criticism turns this mirror on the act of thinking itself. This kind of approach takes for granted, first, a stable and real world, and second, the possibility of objectively describing it. Difference of all kinds is disregarded. 'Diffraction' is the alternative to reflection that Barad offers. ${ }^{10}$ This involves 'reading insights through one another in attending to and responding to the details and specificities of relations of difference and how they matter' (Barad 2007, 71). Whereas reflection is about sameness and internal identity, hallmarks of representationalist philosophies, diffraction has a differential structure. Despite diffraction retaining a visual reference, as it is employed to reveal the problems of representation, diffraction is not a metaphor for Barad: she insists, 'my method will not entail analogical argumentation' (ibid., 88). In this either-or model-which includes a schematic diagram (ibid., 89-90) - if something is not metaphorical, then it has literal and material significance. Diffraction literally and materially constitutes difference. And for Barad, mediation is not part this.

"The ubiquitous pronouncements that experience or the material world is "mediated" have offered precious little guidance about how to proceed. The notion of mediation has for too long stood in the way of a more thoroughgoing accounting of the empirical world.' (ibid., 152)

Mediation remains a representational notion in her account, serving representation's ontological separation of objects, and coming between knower and known. Thus, metaphor's material role in method is absent from Barad's account. New materialist media theory, which focuses directly on the material processes of mediation, offers an opportunity to think about this problem.

\section{Embracing Metaphorical Relations: Metaphor as Material Process of Mediation}

When mediation is examined in terms of a constitutive role, as in Barad's analysis, the metaphorical processes involved in methods can be better appreciated. The expanded media perspective, which emphasises mediation's role in material and social relations, offers an opportunity for a rethinking of metaphor that would set up no such opposition between metaphor and material. Metaphor is a key issue in twentieth-century philosophy, in both analytic and continental traditions. Some key questions include: is metaphor a supplemental operation of language or is it an essential part of consciousness? Can we oppose metaphor and systematic logic? What is the relation between metaphorical language and the world? Is there an end to metaphor? On the one hand, there are familiar and received understandings of metaphor, like this dictionary definition:

\footnotetext{
${ }^{10}$ Barad borrows this term from Donna Haraway (1997), and it has been taken up in various ways. Iris van der Tuin (2014) explores 'diffractive reading' through Alfred North Whitehead's philosophy, for example.
} 
In general, a metaphor ascribes to some thing or action $\mathrm{X}$ a property $\mathrm{Y}$ which it could not literally possess in that context. Responding to this anomaly, the hearer or reader infers that what is meant is that $\mathrm{X}$ is $\mathrm{Z}$, where $\mathrm{Z}$ is some property suggested by $\mathrm{Y}, \mathrm{X}$ or the interaction of the two, that can be literally true of $X$ in some context. (Childs \& Fowler 2005, 139)

Here, metaphor is an analogical description that stands at some remove from the thing it describes. This is the classical understanding built on the linguistic model of representation. On the other hand, it is possible to conceive metaphor beyond representation. Metaphor's philosophical pedigree shows us that it was never just about analogy - that it is a central element of consciousness, and it plays a constitutive role in language, in reality, in theoretical abstractions. In one of the most famous of these accounts, Jacques Derrida (1974) argues that metaphor is fundamental to concepts and to thinking: our assumptions about language and concepts being separate are misguided, as they are, in fact, co-constitutive of each other. Another idea - one that Derrida rejected - is that metaphor is a historical process. ${ }^{11}$ The interpretation of language relies upon a set of contingent circumstances that develop according to the meaning systems of different eras. Even in the wake of these efforts to problematise stable identity and displace binary thinking, representation and referentiality are not uncontested ideas. Their symbolic aspects continue to bemuse any determinations or diagnoses. The legacy of this philosophical debate, which raises significant methodological challenges, can be seen in various humanities approaches today. ${ }^{12}$ Metaphor was never just about the analogical transfer of meaning to an imagistic representation: it is a necessary part of human relation to the world; new metaphors create new realities. Thus, while nonrepresentational approaches to metaphor are not entirely new, there are nonetheless differences with more recent, new materialist ones.

Reading metaphor in a new materialist key, we can discern a material process. This perspective can nuance our understanding of metaphor's relations to matter and meaning, showing how one is bound up with the next, rather than existing on separate levels. Its context, therefore, rather than consisting solely of symbolic content, is one of material entanglement with its surroundings. It is constituted of a relationship with bits of the worldwhich affects both ends of the relation in turn. If the traditional definition of metaphor is that it offers an understanding of something - through a secondary and mediated experience - then the new materialist perspective on metaphor is that it offers primary experience through something. This experience is mediated, but we understand the process of mediation as a performative enactment of the things it is entangled with. Metaphor, in this regard, is a primary and constitutive experience. Kember and Zylinska's analysis, for instance, shows how mediation is a form of constitution. Metaphor has been considered in this light before. Approaching materiality in a similar way, ${ }^{13}$ Ian Bogost (2012) argues that metaphor is a vital practice and 'metaphorism' should be considered as a basic method in how we apprehend and experience the world. We are bound to linguistic descriptions of things and experiences, and anthropomorphic, human-centric metaphors help us make sense of these. Nevertheless, objects and processes in the world remain distant to us. Trying to describe something in objective terms is challenging, but it also obscures the object:

\footnotetext{
${ }^{11}$ Pierce $(2014,26-27)$ discusses this point.

${ }^{12}$ Lakoff \& Johnson (2003), for example, explore metaphor in this context.

${ }^{13}$ Bogost writes from the perspective of object oriented ontology. See also Meillassoux's (2008) essay in this area.
} 
Counterintuitive though it may seem, the characterization of an experience through supposedly objective experience and external mechanisms leads us farther from, not closer to, an understanding of the experience of an entity. (Bogost 2012, 63)

Bogost admits that metaphorism, which necessarily involves anthropomorphism, can bring us closer to an understanding. Any account of material-performative relations has to accept this, and enact a practice of metaphor that accepts these terms, rather than working from within an exclusionary structure, as in the representation-performativity debate.

The question of how things exist in the world is no longer one of interacting singularities, but of how they relate to each other and are mediated in multiple complex and indeterminate ways. The media through which we experience the world are not neutral technologies or techniques; these surroundings are not straightforwardly delineable. This is not to erase the category of media altogether, as some anti-ontological approaches have done. ${ }^{14}$ Rather, it is to shift the concern of media theory from object for humans to process of the world, and to rethink what mediation is in the first place. We have to comprehend this in a nonexclusionary light to avoid the pitfalls of a simplistic performativity-representation relationship. This involves looking beyond metaphor's human import and considering its material implications in the spirit of new materialism's emphasis on non-linguistic, nonrepresentational elements. Embracing metaphor as a significant methodological term for new materialist media theory, a move this essay pushes for, brings it into dialogue with the method, media, materiality network that new materialism explores.

\section{Film-as-Theory}

This section examines a recent trend in media studies that claims film images as a kind of visual theory - as well as related discourses on film-as-philosophy and film-as-thinking. ${ }^{15}$ Photographic and cinematographic media are frequently examined in the context of their performative and material relations to the world. Kember and Zylinska (2012), for instance, argue that photographic media enact duration, rather than merely reproducing it by mechanical and representational means. ${ }^{16}$ Cinema is also being reconsidered in this light, as scholars work to close the gaps between film images, the world, and theory (Pisters, 2003; del Río, 2008; Ivakhiv, 2013). Recent thinking on cinema's specificity as a medium has led in some cases to the claim that, rather than needing a subsequent and aloof theorising, cinema itself is a form of audiovisual theory. To give an example of this process, we can consider how Volker Pantenburg (2015) treats Jean-Luc Godard and Harun Farocki as 'image researchers'. Pantenburg explains how the filmmakers achieve this:

Both directors had made the question of the image in its manifold guises their central concern. Both navigated in unmarked territory between fiction and documentary, using cinema and its tools as a genuine mode of research. Both took moving images seriously as agents of theory, and used film history as a treasure trove of material for

\footnotetext{
${ }^{14}$ Consider these lines, for example:

Perhaps such an anti-ontological approach to media, a radical opening of the analytical domain to any kind of medial process, has been more productive and theoretically challenging than any attempt, however convincing, at answering the question of what media are. (Horn 2008, 8)

${ }^{15}$ Bloomsbury's Thinking Cinema series, Constable (2006), and Phillips (2008), for instance, explicitly address these themes.

${ }^{16}$ Bernd Herzogenrath (2015) also follows this Bergsonian line.
} 
thinking visually. Not least, they were tremendous film critics and writers who accompanied their films and TV programs with a corpus of highly original writings. $(2015,8)$

Here, images work as a kind of critique. In their different essayistic styles, Godard and Farocki have always blurred the line between fiction and documentary, art and the external world. This makes their films amenable to academic theoretical explication, but Pantenburg's claim is that the films are a form of theory themselves. The practice of images becomes reflexive critique in these filmmakers; in the terms of this essay, Godard and Farocki's cinematic expression is performative. Theorists of performativity will say that the materiality of images is self-evident, and that it stands before language and representational structures. In this way, Godard lets the visual speak for itself: "The image comes before the structure; it adheres to its own laws and brings about theoretical "concepts" in the conjunction of images themselves' (Patenburg 2015, 27). For Pantenburg, Godard's images enact a sufficient critique of themselves, and further, abstracted theorising would be excessive.

Academic theory takes place predominantly in a textual form. Pantenburg traces the etymology of the word theory to its visual roots, enquiring if a visual theory is possible. But despite these original visual connotations, the practice of contemporary media theory should not abandon metaphor in favour of following performative-material relations and processes. Pantenburg (2015) claims that that Godard and Farocki's work offers a non-textual theory through their reflexive image critique. But this notion deprecates metaphor and representational structures by opposing images to textuality. The film-as-theory discourse, as elaborated by Pantenburg, is based on an exclusionary structure of performativity. From a new materialist perspective, images do not break from metaphor: they retain a metaphorical relation to the world, which is both representational and material at the same time. In these terms, cinematic media and theory are not separate in the first place: theory is not a theoretical reduction or reproduction of the first. Cinema and theories of cinema undergo similar processes of mediation as they circulate in the world. Instead of thinking about cinema as a primal creative expression and theories of cinema as temporary enactments of secondary processes, and always conceiving these things apart, we can focus on the metaphorical relations in each. Treating these things as entangled processes does not reduce one to the other through analogy; theories of cinema are bound up with the images and experiences they describe. This entanglement is inevitable if we follow Barad's insights on entanglement and Kember and Zylinska's extension of these by reconceiving media objects as processes of mediation. These conditions of entanglement and process do not oppose or succeed attempts to describe them. Metaphor also participates and unfolds through these conditions.

\section{Conclusion}

The expansion of the media concept towards processes of mediation demonstrates that media are not simply the cultural, artificial objects that we assume them to be. They lie in between bodies and things, and are the means through which we perceive these things. This essay shows that metaphor is a constitutive part of the world, and to remove metaphor from the conversation on mediation and materiality would be misguided. They do not transcend metaphor. New materialism theory sometimes falls prey to this form of transcendentalism by employing its own dualisms: opposing performativity, materiality, and practices to representation, and affirmation to critique. The older terms are considered unproductive to 
critical enquiry. ${ }^{17}$ We must go on interrogating the methodological underpinnings of both established and newer frameworks, and acknowledge the great deal of complexity and insight in representational approaches. From the new materialist perspective on media, language and technology share critical contexts, which moved from an instrumental understanding of their function to a constitutive one. Through this shared context, we have reached conclusions on the processes of mediation involved in metaphor, which previously would not have been examined together. This type of questioning must go on-mediation needs to continue being addressed in terms of its materiality. We saw in this essay how a different sense of mediation contributes to an alternative understanding of metaphor, which appreciates how it exceeds a representational and rhetorical function. Media theory thus becomes essential point of reference for new materialist thought. It offers a sophisticated view on how the world around us is made up of processes of mediation. This is a valid and important perspective. At the same time, it would be counterproductive to expand the critical terms of mediation to such a degree that they stand in as a universal critical category. This line of enquiry into mediation and materiality may lead in some cases to their ultimate conflation. We have to push back against advocating a totalising concept that considers all life and actions and interactions as media, mediated, or medial.

\section{References}

Barad, K. (2007) Meeting the Universe Halfway: Quantum Physics and the Entanglement of Matter and Meaning. Durham: Duke University Press.

Bogost, I. (2012) Alien Phenomenology: or, What it Means to Be a Thing. Minneapolis: University of Minnesota Press.

Childs, P. and Fowler, R. (2005) The Routledge Dictionary of Literary Terms, $3^{\text {rd }}$ ed. London: Routledge.

Constable, C. (2006) Thinking in Images: Film Theory, Feminist Philosophy, and Marlene Dietrich. London: Palgrave.

del Río, E. (2008) Deleuze and the Cinemas of Performance. Edinburgh: Edinburgh University Press.

Derrida, J. (1974) 'White Mythology: Metaphor in the Text of Philosophy', trans. F. C. T. Moore. New Literary History, 6 (1): 5-74.

Dolphijn, R. and van der Tuin, I. (eds) (2012) New Materialism: Interviews \& Cartographies. Ann Arbor: Open Humanities Press.

Gauntlett, D. (2015) Making Media Studies: The Creativity Turn in Media and Communications Studies. New York: Peter Lang.

Haraway, D. (1997) Modest_Witness@Second_Millenium.FemaleMan_Meets_OncoMouse: Feminism and Technoscience. London: Routledge.

\footnotetext{
${ }^{17}$ Chapter 5 in Dolphjin and van der Tuin's collection is an example of this (2012).
} 
Herzogenrath, B. (2015) 'Matter that Images: Bill Morrison's Decasia'. In Media Matter: The Materiality of Media, Matter as Medium. London: Bloomsbury

Horn, E. (2008) 'There are no Media', Grey Room, 29: 6-13.

Ivakhiv, A. (2013) Ecologies of the Moving Image: Cinema, Affect, Nature. Waterloo, ON: Wilfrid Laurier University Press.

Kember, S. and Zylinska, J. (2012) Life after New Media: Mediation as a Vital Process, MIT Press.

Lakoff, G. and Johnson, M. (2003) Metaphors We Live By. Chicago: University of Chicago

Press.

Law, J. (2004) After Method: Mess in Social Science Research. London: Routledge

Meillassoux, Q. (2008) After Finitude: An Essay on the Necessity of Contingency, R. Brassier (trans). London: Continuum.

Noys, B. (2010) The Persistence of the Negative: A Critique of Contemporary Continental Theory. Edinburgh: Edinburgh University Press.

Parikka, J. (2011) 'Media Ecologies and Imaginary Media: Transversal Expansions, Contractions, and Foldings', Fibreculture, 17: 34-50.

------- (2015) A Geology of Media. Minnesota: University of Minneapolis Press.

Pantenburg, V. (2015 [2006]) Farocki/Godard: Film as Theory. Amsterdam: Amsterdam University Press.

Phillips, J. (2008) Cinematic Thinking: Philosophical Approaches to the New Cinema. Stanford: Stanford University Press.

Pierce, A. E. (2014) 'Towards a New Romanticism: Derrida and Vico on Metaphorical Thinking', Thesis Eleven, 123 (1): 17-40.

Pisters, P. (2003) The Matrix of Visual Culture: Working with Deleuze in Film Theory. Stanford: Stanford University Press.

Thrift, N. (2008) Non-Representational Theory: Space, Politics, Affect. London: Routledge

Timeto, F. (2015) Diffractive Technospaces: A Feminist Approach to the Mediations of Space and Representation. Surrey: Ashgate.

van der Tuin, I. (2014) "Without an Analytical Divorce from the Total Environment": Advancing a Philosophy of the Humanities by Reading Snow and Whitehead Diffractively', Humanities, 3: 244-63.

van Raamsdonk, M. (2010) 'Building up Spacetime with Quantum Entanglement', General Relativity and Gravitation, 42 (10): 2323-2329 
Niall Flynn is PhD candidate at Lincoln School of Film \& Media, University of Lincoln. His research explores recent media theory that rethinks the material and methodological implications of media technologies and processes of mediation, particularly from a mediaecological perspective. His writing has appeared in Alphaville, Cinema: Journal of Philosophy and the Moving Image, and Teaching Media: Cinema Journal Teaching Dossier.

Email: nialljf@gmail.com 